\title{
Nurses' Experiences of Using the Liverpool Care Pathway Plan in Hospitalized Patients with Heart Failure in the End-of-Life Stage: A Qualitative Content Analysis
}

\author{
Randi Hove1,2, Nina Fålun 1,3, Bengt Fridlund 1,3,4* \\ ${ }^{1}$ Institute of Nursing, Department of Health and Social Sciences, Bergen University College, Bergen, Norway \\ ${ }^{2}$ Department of Heart Disease, Førde Hospital, Førde, Norway \\ ${ }^{3}$ Department of Heart Disease, Haukeland University Hospital, Bergen, Norway \\ ${ }^{4}$ School of Health and Welfare, Jönköping University, Jönköping, Sweden \\ Email: "bengt.fridlund@ju.se
}

Received 13 July 2016; accepted 21 August 2016; published 24 August 2016

Copyright (@) 2016 by authors and Scientific Research Publishing Inc.

This work is licensed under the Creative Commons Attribution International License (CC BY).

http://creativecommons.org/licenses/by/4.0/

(c) () Open Access

\begin{abstract}
Background: The introduction of care pathway plans for end-of-life cares such as the Liverpool Care Pathway (LCP) reveals a unique possibility for inter professional collaboration. Knowledge of symptom relief and how to meet the patients' needs at the last stage of the palliative phase are essential for the nurses' approach and care actions, but the documentation of such implementations is still rare and sometimes criticized. Aim: To explore and describe nurses' experiences of using the LCP plan with patients hospitalized with heart failure at the end-of-life stage. An explorative design was applied, using qualitative content analysis of 20 interviews with nurses practicing the LCP plan in two district hospitals in Norway. Results: The nurses found the LCP plan as quality assurance for treatment and care in patients with heart failure in the last hours and days of life. The use of the LCP plan implied: 1) individualized adjustment, 2) symptom relief and 3) a holistic approach. Conclusion: Nurses experienced that using the LCP plan as a comprehensive action plan contributed in the decision making process and improved inter professional communication. Using the LCP plan should be seen as a tool to practice individualized and holistic nursing to patients at the end-of-life and their families, as well as a purposeful relief of symptoms associated with heart failure.
\end{abstract}

\section{Keywords}

End-of-Life Care, Heart Failure, Nursing, Palliative Care, Qualitative Method

\footnotetext{
${ }^{*}$ Corresponding author.
}

How to cite this paper: Hove, R., Fålun, N. and Fridlund, B. (2016) Nurses' Experiences of Using the Liverpool Care Pathway Plan in Hospitalized Patients with Heart Failure in the End-of-Life Stage: A Qualitative Content Analysis. Open Journal of Nursing, 6, 591-599. http://dx.doi.org/10.4236/ojn.2016.68063 


\section{Introduction}

Palliative care involves the active treatment and care of patients with incurable diseases and a short life expectancy. This end-of-life care aims to strengthen patients' possibility to accept death and prepare families for grief and bereavement [1]. Thus, its goal is to offer the best possible quality of life for both patients and their families. This ambition is also reflected in WHO's definition [2] of palliative care that can be seen, among others, in the hospice philosophy (Box 1). Effective palliative care at the outset can contribute to a positive clinical outcome as symptom alleviation and it improves patients' satisfaction with care [3]. Yet, even for experienced nurses, communication with patients and close relatives about death might be stressful, and emotional and existential reactions from patients and families might be difficult to handle [4] [5]. A coherent and clear theoretical framework for communication in palliative care is thus of utmost importance for nurses working in this area [6] [7]. Basic prerequisites for optimal palliative care are that nurses have the necessary professional expertise in knowledge, skills and attitudes [8] [11]. The introduction of care pathways plans for end-of-life care also reveals an unique possibility for interprofessional collaboration [12] [13].

\section{Box 1: The WHO definition of palliative care.}

\footnotetext{
"Palliative care is an approach that improves the quality of life of patients and their families facing the problems associated with life-threatening illness, through the prevention and relief of suffering by means of early identification and impeccable assessment and treatment of pain and other problems, physical, psychosocial, and spiritual.” ([2], p. 10)
}

The Liverpool Care Pathway (LCP) [14] is a care plan for patients in their last hours and days of life. The LCP plan is based on the hospice philosophy and was developed in England in the early 1990s. Today, it is internationally recognized as a model for support and care in patients at the end-of-life [4] [12], but not without criticism stating it is impossible for nurses and physicians to predict when death is imminent, why the decision to set a patient on the pathway is at worst self-fulfilling [15] [16]. Regardless, the LCP provides evidence-based guidance in relation to various aspects of end-of-life care such as recommended prescription of medication and discontinuation of unnecessary medication, psychological support, spiritual care, and not the least care of families [17] [18]. The LCP discontinues if the patients' condition improves, but resumes if deterioration recurs.

Heart failure is a progressive and irreversible clinical syndrome caused by different cardiac dysfunctions [1]. Advances in healthcare and reduction of mortality help explain the high prevalence of heart failure, as there is an ageing of the population and prolonged survival of patients suffering from ischemic heart disease, hypertension and a trial fibrillation [19]-[21]. Patients with heart failure are mainly treated with medication, but before endof-life care, devices and interventions such as the implantable cardioverter defibrillator (CRT-D), ventricular assist device (LVAD) or heart transplantation might be appropriate [22].

Despite both bio-medical and existential needs at the end-of-life, individual care plans for patients with heart failure are seldom implemented [1] [23] [24]. This might be due to the often unpredictable prognosis of heart failure, making the "right time" for the decision on end-of-life care challenging [5] [25]. Nevertheless, knowledge of symptom relief and how to meet the patients' needs at the last stage of the palliative phase are important for the nurses' approach and care actions [17] [19] [25]. Nurses' experiences of using a palliative care plan such as the LCP plan are essential, but the documentation of such implementations is rare and sometimes contradictable. Therefore, the aim of this study was to explore and describe nurses' experiences of using the LCP plan in hospitalized patients with heart failure at the end-of-life stage.

\section{Methods}

\subsection{Design, Setting and Method Description}

The study used an explorative design based on qualitative content analysis, to provide knowledge and understanding of nurses' experiences of using the LCP plan. The study was carried out in two district hospitals in southwestern Norway. Qualitative content analysis was chosen, as it can be applied to analyze individual experiences. Using both manifest and latent content analyses provides more insightful and meaningful findings than using only one approach. Manifest analysis focuses on the visible and literal components in the text, while latent analysis aims to reflect the underlying meaning of what the text talks about [26]. 


\subsection{Participants and Criteria}

The inclusion criterion was nurses who had experience with using the LCP plan with a minimum of three patients with heart failure at the end-of-life. The exclusion criterion was nurses who did not mastered the Norwegian language. Both the inclusion and exclusion criteria were set do to assure the quality of the interviews. To ensure a broad sample with maximum variation, a strategic sampling [27] of 20 nurses was carried out, where participants varied in terms of age, sex, educational level, years of nursing experience and geographical area (Table 1).

\subsection{Interviews}

The three authors, all with experience on the subject and methods, developed an open interview guide based on the three elements of the LCP plan [28]. Two pilot interviews with nurses well-experienced in using the LCP plan were conducted by the first author to test the interview guide and process. These pilot interviews are excluded in the study and did not result in any adjustments. The interviews were conducted by the first author, who aimed to establish a relation to the participants. The opening question was: "What are your experiences with using the LCP plan in relation to patients suffering from heart failure?” Follow-up questions to explore the experiences with each of the three parts of the LCP plan were; "What was the most challenging topic while using the LCP plan?", "What area was the most challenging for the patient?", "How well did the collaboration with the physicians work out?", "How were families taken care of?” The participants were encouraged to provide more in-depth information, for example by being asked to elaborate answers with concrete examples [27].

\subsection{Data Collection}

Participants were contacted through their head nurse and asked if they were willing to participate in the study. The 20- to 60-minute long tape-recorded interviews took place from December 2013 to January 2014 in an undisturbed place at their own departments.

Table 1. Socio-demographic and clinical characteristics of the nurses using the Liverpool Care Pathway plan in hospitalized patients with heart failure in the end-of-life stage.

\begin{tabular}{|c|c|}
\hline Nurses & 20 \\
\hline \multicolumn{2}{|l|}{ Age (years) } \\
\hline-29 & 4 \\
\hline 30 - 39 & 4 \\
\hline $40-49$ & 6 \\
\hline $50-59$ & 5 \\
\hline 60- & 1 \\
\hline \multicolumn{2}{|l|}{ Sex } \\
\hline Male & 6 \\
\hline Female & 14 \\
\hline \multicolumn{2}{|l|}{ Geographic area } \\
\hline Urban area & 8 \\
\hline Rural area & 12 \\
\hline \multicolumn{2}{|l|}{ Educational level } \\
\hline Bachelor & 9 \\
\hline Specialist education & 11 \\
\hline \multicolumn{2}{|c|}{ Years of nursing experience } \\
\hline-3 & 1 \\
\hline $3-9$ & 5 \\
\hline $10-19$ & 6 \\
\hline $20-29$ & 5 \\
\hline 30- & 3 \\
\hline
\end{tabular}




\subsection{Data Analysis}

Data analysis was carried out stepwise according to Graneheim \& Lundman's [26] six steps of qualitative content analysis. The interviews were analyzed and transcribed verbatim by the first author. An awareness of preunderstanding supported the authors to bracket the data [27]. In the analysis process, the intention was to remain true to the text and preserve contextual meanings in both the manifest and the latent content. The text was both listened to and read repeatedly by the authors to obtain a sense of the whole. Significant meaning units that matched the aim of the study were identified, condensed and coded. Differences and similarities among various codes were compared in order to sort out sub-categories and categories (Table 2). The codes were grouped into 38 subcategories which were abstracted into three categories. These categories reflected the central message and constituted the manifest content, i.e. what the text says. These categories were then tied together and further abstracted into a theme reflecting the underlying meaning, i.e. the latent content (Table 3). To ensure strength and trustworthiness of the results, the text and selected segments were examined repeatedly. The authors critically examined and discussed until consensus was reached [26] [27].

\subsection{Ethical Considerations}

The study conformed to the principles outlined in the Declaration of Helsinki and obtained ethical approval from the Norwegian Social Science Data service (36313/2013). The director and the head nurses of the departments gave their written consent before each participant was approached. Verbal and written information was given to each participant to obtain informed consent, and they were also reassured that they could withdraw from the study at any time. Confidentiality was ensured in the study by storing the interview material according to current data regulations

\subsection{Findings}

The emerging theme emphasized LCP plan as a form of quality assurance for treatment and care for patients with heart failure in the last hours and days of life. The LCP appeared to be helpful in assuring quality of treatment and nursing care in the end-of-life in patients suffering from heart failure. The LCP was a clear and necessary action plan for patients with heart failure at the end-of-life stage where the objective was to improve the care in the last days and hours of life. Moreover, the transition from usual care to the LCP plan was thoroughly evaluated by an interprofessional team of nurses and physicians, and all reversible causes for deterioration had to be considered. In using the LCP plan, the importance of being a well-educated nurse to make correct assessments about timing was central. The assessments and conversations between nurses and physicians before the transition to the LCP plan were, according to the participants, essential when evaluating the patient's physical and mental health.

Table 2. An example of the data analysis procedure regarding the emerged abstraction levels in nurses' experiences of using LCP plan to patients with heart failure in the end-of-life stage.

\begin{tabular}{|c|c|c|c|}
\hline Meaning units & $\begin{array}{l}\text { Condensed } \\
\text { meaning units }\end{array}$ & Sub-category & Category \\
\hline $\begin{array}{l}\text { "Great variation in the need of information both for } \\
\text { patients and relatives...some are very well prepared" }\end{array}$ & $\begin{array}{l}\text { Great variation in need of } \\
\text { information }\end{array}$ & Adapted information & $\begin{array}{l}\text { Adapted } \\
\text { individually }\end{array}$ \\
\hline $\begin{array}{l}\text { "Inform about priest available-do not need to be a } \\
\text { Christian to have a meeting with the priest" }\end{array}$ & $\begin{array}{l}\text { Offer a meeting with the } \\
\text { priest }\end{array}$ & $\begin{array}{l}\text { Take care of spiritual and } \\
\text { existential needs }\end{array}$ & $\begin{array}{l}\text { Adapted } \\
\text { individually }\end{array}$ \\
\hline $\begin{array}{l}\text { "LCP ensures that the evaluation of deactivation of } \\
\text { CRT-D is done" }\end{array}$ & Deactivation of CRT-D & Avoid electro shock & $\begin{array}{l}\text { Symptom } \\
\text { relief }\end{array}$ \\
\hline $\begin{array}{l}\text { "Give furosemide through the last few days to avoid } \\
\text { dyspnea to dying patients with heart failure" }\end{array}$ & $\begin{array}{l}\text { Furosemide important } \\
\text { medication }\end{array}$ & Adapted symptom relief & $\begin{array}{l}\text { Symptom } \\
\text { relief }\end{array}$ \\
\hline $\begin{array}{l}\text { "LCP contributes to a new focus for everyone } \\
\text { involved...more calmness" }\end{array}$ & $\begin{array}{l}\text { Changes focus from } \\
\text { curation to palliation }\end{array}$ & Acceptance of the last stage & $\begin{array}{l}\text { Holistic } \\
\text { approach }\end{array}$ \\
\hline $\begin{array}{l}\text { "Primary nursing is the better-to get to know each } \\
\text { other" }\end{array}$ & Make continuation & Security and stability & $\begin{array}{l}\text { Holistic } \\
\text { approach }\end{array}$ \\
\hline
\end{tabular}


Table 3. Overview of quotations, condensed meaning units, sub-categories, categories and theme regarding the emerged abstraction levels in nurses' experiences of using LCP plan to patients with heart failure in the end-of-life stage.

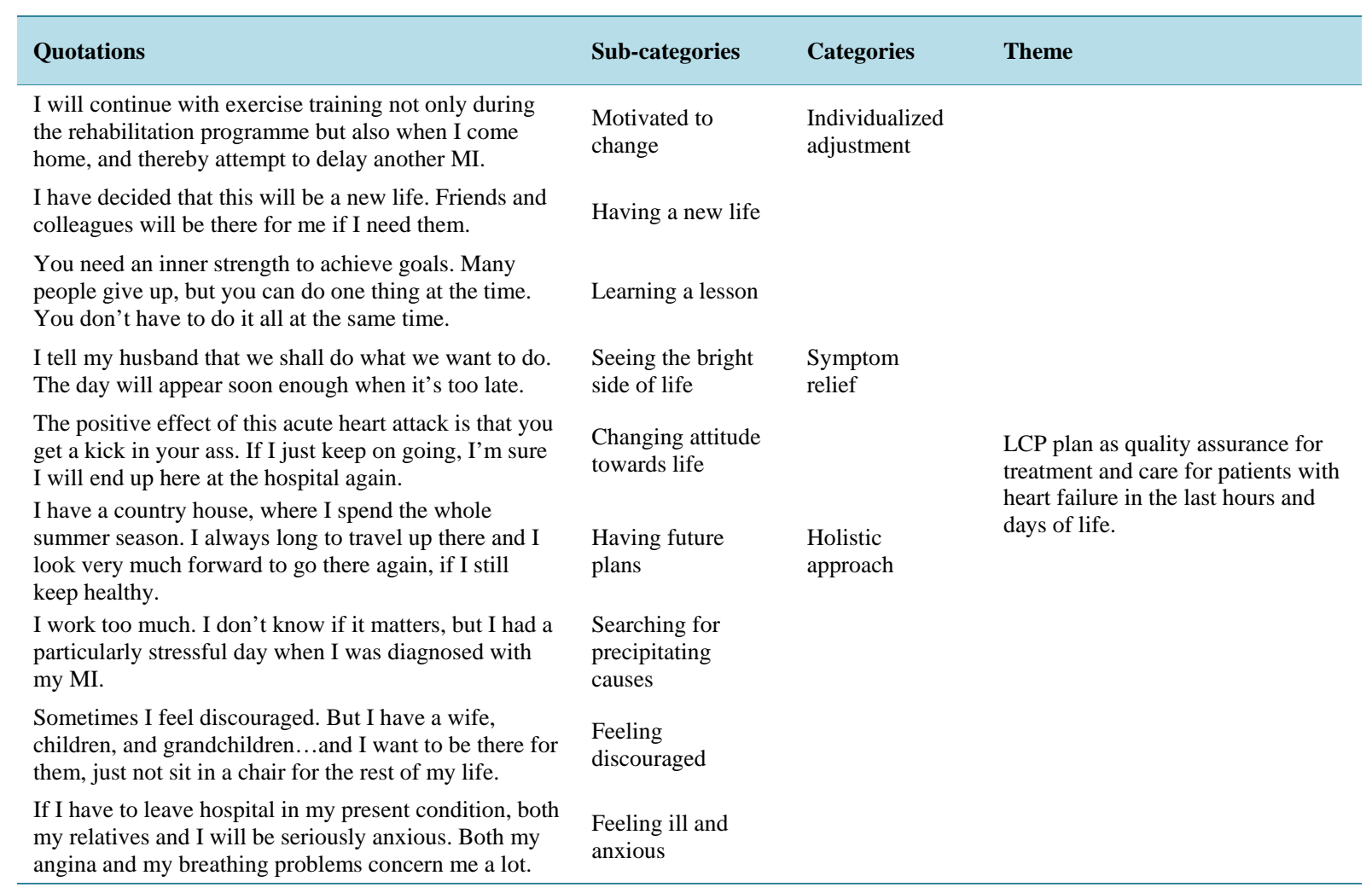

\subsection{Individualized Adjustment}

The LCP plan was experienced by participants as increasing their awareness of the aspects of end-of-life. To meet the patients' unique experiences and needs, nurses had to make individual adjustments: "The wife and daughters were concerned about how he (the patient) would accept that the treatment did not have any effect this time, ...he could not come home anymore..., they were not yet ready to let the physician tell the patient....This was done the next day, and then they were ready....”. The nurses confirmed that the individualized adjustments contributed to better understanding and cooperation between them and the patients. The consultations with patients and families, which were well-prepared and conducted in a good atmosphere and with both the nurse and the physician present, were regarded as highly important. The communication should be reciprocal to avoid misunderstandings.

\subsection{Symptom Relief}

A high level of competence both in palliative care and cardiac nursing was of importance to relieve symptoms. When starting the LCP plan, deactivation of the CRT-D had to be discussed, but dyspnea was graded as the main problem: "It seemed so tiring...she struggled with heavy breathing...she gurgled actually...it came so suddenly...my colleague nurse had just been there...but they (the family) had to call us. I came back... late...they thought...looking at their mom...she was given both furosemide and morphine...it only took a few minutes before her breathing improved...after she had received furosemide more frequently...”. The nurses experienced that it was challenging to titrate Furosemide for optimal symptom relief. They needed to know the medications well, both its effects and side effects. In cooperation with patients and families, it was easier to make a good evaluation and obtain symptom relief.

\subsection{Holistic Approach}

A holistic approach was necessary to see patients in their context and to understand the interaction within fami- 
lies. Creating an environment of patients with heart failure at the end-of-life stage, where all unnecessary equipment are removed to provide a "human atmosphere" was of utmost importance, especially for symptom reliefs of all types. The introduction of the LCP plan changed the focus from curing and life-prolonging treatment to optimal and immediate pain relief: "It was very special... when it was decided...everyone was suddenly more peaceful...everything changed...for the better...Now it was more quiet...And now they wanted the minister present...and they sat and dined and talked together...I think the patient felt a kind of calmness...he was more peaceful too...not struggling...everyone was more peaceful...”. The nurses revealed the importance of education in the use of the LCP plan, both for themselves and physicians, to be able to make "the right decisions" on when to include the patient on the LCP plan. A common assessment based on good communication and knowledge about the patient was important, but the complexity of the situation sometimes caused delays in applying the action plan.

\section{Discussion}

\subsection{Results Considerations}

The nurses in our study graded the LCP plan as important for improving the quality of support and care in the last days and hours for patients with heart failure at the end-of-life stage. To succeed in the implementation of the LCP plan, a good training program was needed. The nurses expressed that common training and education together with physicians in the use of the LCP plan was necessary. Such improvement tools are supportive for nurses and physicians to predict when death is imminent, and thereby make the correct decision to set a patient on the pathway. These results reinforce the conclusions from recent studies [7] [15]-[17], that there are differences in opportunities for good quality of care in a palliative care unit compared to an internal medicine ward. A holistic approach, i.e. meeting the patients' total needs, is of utmost importance as individualized and tailored nursing is essential for patients, but also their families.

\subsection{Individualized Adjustment}

The LCP plan is documented in such a way that all information is written by the nurses on a printed form. The nurses regretted that the space for writing information was too limited. The strict rules for translation, due to copyright reasons, also made the content confusing and could lead to misunderstandings when filling up the form. This supports the importance of regular training and mentorship to assure the quality of care when using the LCP [15]-[17]. The nurses confirmed the challenge of finding the right time to introduce the LCP plan, an experience they shared with the physicians. There are patients suffering from many symptoms, but often experience a relief with correct treatments. The time it takes for patients to feel the benefits of treatment is however difficult to establish, which thus may result in delay in the start of the LCP plan. Also, Dee and Endacott [6] in their interviews with nurses and physicians found that "the right time" to initiate the LCP plan was problematic, independent of the patient's diagnosis. Accordingly, end-of-life care has to be individually adjusted.

The results of our study also found the LCP plan to be significant in securing quality of care as well as quality assurance in this individualized adjustment. Several studies describe that good communication skills are important to succeed in using the LCP plan [12] [19] [27]. In line with Veerbeek et al. [11], the nurses in our study experienced that the LCP plan was important for a more individualized and tailored communication. In line with Di Leo et al. [29] and O’Hara [21] our study calls attention to the importance of using the interprofessional approach, with physicians and nurses doing the assessments together. Designing a plan together contributed to a continual assessment for individualized and tailored adjustment, leading to coordinated and coherent information not only for patients but also for their families. When the information was understood and nurses were able to give individualized adjustments, this constituted the backbone to sufficient relief, a conclusion also shared by Hanks et al. [2].

\subsection{Symptom Relief}

Dyspnea was pointed out as the most crucial symptom to relieve, and the use of furosemide as the standard medication in the LCP plan was therefore an important finding in the study. Accordingly, the nurses had years of experience in titrating furosemide to relieve symptoms for patients with heart failure at the end-of-life stage. There were patients who had continuous infusions of furosemide until the decision was made to introduce the 
LCP plan. This infusion had small effect on urinal production, and only a partial effect on dyspnea, which is in line with Hanks et al. [2]. Nurses in our study found that dry mouth was relieved by regular oral hygiene and small mouthfuls of water, ice or fruit cubes, as long as patients were able to swallow. In the Srivastava and Ting study [30] where patients had been denied drinking from the time the LCP plan started, the authors underline this grave misunderstanding and the importance of education in palliative care. Ordination of medication as a separate point in the LCP plan results to a quicker response to symptoms, as nurses could administer the medications on indication following the algorithms [28]. Our study implies that nurses need to be able to show empathy and understanding, and use individualized adjustments to take care of patients' primary needs.

\subsection{Holistic Approach}

Our study found that when the quest for effective treatment was finished and the transition to the LCP care was accepted, the focus changed for all parties involved. The nurses experienced more tranquility and a peaceful atmosphere around patients. The last days of life are characterized by sorrow, as well as crisis when patients have a sudden change in prognosis and patients and families are not prepared. The holistic approach thus has to focus on the patients' and families' total needs through the end-of-life. In line with Hanks et al. [2], the nurses in our study valued open, honest and coordinated communication as essential meeting all those needs. Further, when patients' conditions worsened making them unable to communicate, a close partnership with families was necessary [9] [15]-[17]. This underlines the nurses' conviction on the necessity of a holistic approach, i.e. the ability to grasp the condition as a contextual whole. Accordingly, the fundamentals in human existence demand a substantial competence from nurses [1].

\subsection{Methodological Considerations}

In a qualitative content analysis, the credibility, dependability, conformability and transferability should be discussed in relation to the trustworthiness of the study [26] [27]. In both the data collection and analysis, credibility was strengthened by the use of an open interview guide, which encouraged nurses to reflect on the phenomenon of using the LCP plan in hospitalized patients with heart failure at the end-of-life stage. In addition, follow-up questions were posed in order to avoid misunderstanding and to explain personal understanding in more detail, strengthening credibility. The interview guide guaranteed that the same open-ended questions were posed to all nurses. Each experience was described by several nurses augmenting a sufficient credibility. And finally, the authors' familiarity with the phenomenon and the fact that two pilot interviews were carried out also contributes to credibility. Dependability was strengthened by the fact that the data analysis sought to "identify" nurses' experiences of using the LCP plan in hospitalized patients with heart failure at the end-of-life. In the analysis, the authors attempted to be open to all experiences that corresponded to the aim. Dependability was increased by the fact that the co-authors were familiar with the methods, and interpretations were compared and revised until a negotiating consensus was reached between authors. Confirmability is considered relevant due to the way the data was systematically and carefully handled, using repeated readings, identification and reflection on the experiences. Furthermore, that that the interviews were performed and transcribed by the main author and all six steps of the analysis was conscientiously used and reported, support confirmability. Experiences are described in as much detail as possible considering text limitations and quotations were used to strengthen and elucidate their content. An awareness of pre-understandings helped the authors to bracket the data. This means being aware of one's own attitudes and being attentive to how these might affect their own interpretations. Transferability was strengthened by the method and recruitment process, which were intended to provide maximum information. Qualitative content analysis is a method with high applicability for exploring human experiences of a phenomenon [27]. With regards to applicability of the study, it is a strength that two hospitals using the LCP plan were included in the study and that the selection took account of nurses' socio-demographic and clinical variables, such as age, sex, and length of experience. Accordingly, 20 nurses were found sufficient as this data was manageable and provided variation in experiences, thereby making our findings relevant for a national outlook from a qualitative method perspective.

\subsection{Conclusion and Implications for Practice}

This study highlights the need for a holistic approach when caring for patients with heart failure at the end-of- 
life ensuring true patient and family involvements. Nursing organization and practice, the nurse role and expertise as well as individual needs and perspectives have to be integrated in the nurses' use of a care plan such as the LCP plan, for patients in their last hours and days of life. The social environment, a professional approach and value-adding measures are particularly relevant for optimal care offered by nurses in the hospital setting. Understanding the complexity of the situation of patients at the end-of-life stage, a palliative care plan such as the LCP plan is essential for reducing patients' symptoms and their families' burden. Therefore, it is substantial to incorporate the present findings in both clinical practice and in healthcare educationdeciding when to set patients on the pathway. More research is needed to establish strategies for individual and family tailored care needs, which is a fundamental condition for holistic nursing care.

\section{References}

[1] Whellan, D.J., Goodlin, S.J., Dickinson, M.G., Heidenreich, P.A., Jaenicke, C., Stough, W.G. and Rich, M.W. (2014) Quality of Care Committee, Heart Failure Society of America. End-of-Life Care in Patients with Heart Failure. Journal of Cardiac Failure, 20, 121-134. http://dx.doi.org/10.1016/j.cardfail.2013.12.003

[2] Hanks, G., Cherny, N.I., Christakis, N.A., Fallon, M., Kaasa, S. and Portenoy, R.K. (2010) Oxford Textbook of Palliative Medicine.4th Edition, Oxford University Press, Oxford.

[3] Shah, A.B., Morrissey, R.P., Baraghoush, A., Bharadwaj, P., Phan, A., Hamilton, M., Kobashigawa, J. and Schwarz, E.R. (2013) Failing the Failing Heart: A Review of Palliative Care in Heart Failure. Reviews in Cardiovascular Medicine, 14, 41-48.

[4] Murphy, D. (2011) The Liverpool Care Pathway Clarity and Focus; Communication and Compression Come from You. International Journal of Palliative Nursing, 17, 529. http://dx.doi.org/10.12968/ijpn.2011.17.11.529

[5] Hjelmfors, L., Strömberg, A., Fredrichsen, M., Mårtensson, J. and Jaarsma, T. (2014) Communicating Prognosis and End-of-Life Care to Heart Failure Patients: A Survey of Heart Failure Nurses’ Perspectives. European Journal of Cardiovascular Nursing, 13, 152-161. http://dx.doi.org/10.1177/1474515114521746

[6] Dee, J.F. andEndacott, R. (2011) Doing the Right Thing at the Right Time. Journal of Nursing Management, 19, 186192. http://dx.doi.org/10.1111/j.1365-2834.2010.01200.x

[7] Constantini, M., Romoli, V., Leo, S.D. and Beccaro, M. (2014) Liverpool Care Pathway for Patients with Cancer in Hospitals: A Cluster Randomised Trial.The Lancet, 383, 226-237. http://dx.doi.org/10.1016/S0140-6736(13)61725-0

[8] Al-Qurainy, R., Collis, E. and Feuer, D. (2009) Dying in an Acute Hospital Setting: The Challenges and Solutions. Journal of Clinical Practice, 63, 508-515. http://dx.doi.org/10.1111/j.1742-1241.2008.01991.x

[9] Goodlin, S.J. (2009) End-of-life Care in Heart Failure. Current Cardiology Reports Journal, 11, 184-191. http://dx.doi.org/10.1007/s11886-009-0027-7

[10] Kulkarni, P.D. (2011) Hospital-Based Palliative Care: A Case for Integrating Care with Cure. Indian Journal of Palliative Care, 17, 64-66. http://dx.doi.org/10.4103/0973-1075.76248

[11] Veerbeek, L. (2008) Care and Quality of Life in the Dying Phase.Thesis. Erasmus MC, University Medical Center Rotterdam, Enschede.

[12] Ellershaw, J.E. and Wilkinson, S. (2011) Care of the Dying: A Pathway to Excellence. 2nd Edition, Oxford University Press, Oxford.

[13] Watts, T. (2012) Initiating End-of-Life Care Pathways: A Discussion Paper. Journal of Advanced Nursing, 68, 23592370. http://dx.doi.org/10.1111/j.1365-2648.2011.05924.x

[14] The Liverpool Care Pathway (LCP). http://www.mcpcil.org.uk/liverpool-care

[15] Neuberger, J.R.B. (2016) The Liverpool Care Pathway: What Went Right and What Went Wrong. British Journal of Hospital Medicine (London), 77, 172-174. http://dx.doi.org/10.12968/hmed.2016.77.3.172

[16] Venkatasalu, M.R., Whiting, D. and Cairnduff, K. (2015) Life after the Liverpool Care Pathway (LCP): A Qualitative Study of Critical Care Practitioners Delivering End-of-Life Care. Journal of Advanced Nursing, 71, 2108-2118. http://dx.doi.org/10.1111/jan.12680

[17] McConnell, T., O’Halloran, P., Porter, S. and Donnelly, M. (2013) Systematic Realist Review of Key Factors Affecting the Successful Implementation and Sustainability of the Liverpool Care Pathway for the Dying Patient. Worldviews on Evidence-Based Nursing, 10, 218-237. http://dx.doi.org/10.1111/wvn.12003

[18] Leo, S.D., Bono, L., Romoli, V. and West, E. (2014) Implementation of the Liverpool Care Pathway (LCP) for the Dying Patient in the Inpatient Hospice Setting: Development and Preliminary Assessment of the Italian LCP Program. American Journal of Hospice and Palliative Medicine, 31, 61-68. http://dx.doi.org/10.1177/1049909113482355

[19] Jaarsma, T., Beattie, M., Ryder, M., et al. (2009) Palliative Care in Heart Failure: A Position Statement from the Pal- 
liative Care Workshop of the Heart Failure Association of the ESC. European Journal of Heart Failure, 11, 433-443. http://dx.doi.org/10.1093/eurjhf/hfp041

[20] Johnson, M., Hogg, K. and Beattie, J. (2012) From Advanced Disease to Bereavement. Oxford University Press, Oxford. http://dx.doi.org/10.1093/med/9780199299300.001.0001

[21] O’Hara, T. (2011) Nurses' Views on Using the Liverpool Care Pathway in an Acute Hospital Setting. International Journal of Palliative Nursing, 17, 239-244. http://dx.doi.org/10.12968/ijpn.2011.17.5.239

[22] McMurray, J.J., Adamoploulos, S., Anker, S.D., Auricchio, A., Böhm, M. and Dickstein, K. (2012) ESC-Guidelines for the Diagnosis and Treatment of Acute and Chronic Heart Failure. European Journal of Heart Failure, 14, 803-869.

[23] Barclay, S., Momen, N., Case-Upton, S., Kuhn, I. and Smith, E. (2011) End-of-Life Care Conversations with Heart Failure Patients: A Systematic Literature Review and Narrative Synthesis. British Journal of General Practice, 61, 4962. http://dx.doi.org/10.3399/bjgp11X549018

[24] Dev, S., Abernethy, A.P., Rogers, J.G. and O’Connor, C.M. (2012) Preferences of People with Advanced Heart Failure: A Structured Narrative Literature Review to Inform Decision Making in the Palliative Care Setting. American Heart Journal, 164, 313-319. http://dx.doi.org/10.1016/j.ahj.2012.05.023

[25] Beattie, J. (2014) Palliative Care for Heart Failure: Challenges and Opportunities. European Journal of Cardiovascular Nursing, 13, 102-104. http://dx.doi.org/10.1177/1474515114521697

[26] Graneheim, U.H. and Lundman, B. (2004) Qualitative Content Analysis in Nursing Research: Concepts, Procedures and Measures to Achieve Trustworthiness. Nurse Education Today, 24, 105-112. http://dx.doi.org/10.1016/j.nedt.2003.10.001

[27] Polit, D.F. and Beck, C.T. (2012) Nursing Research. Generating and Assessing Evidence for Nursing Practice. 9th Edition, JB Lippincott Williams \& Wilkins, Philadelphia.

[28] Ellershaw, J. (2007) Care of the Dying: What a Difference an LCP Makes! Palliative Medicine, 21, 365-368. http://dx.doi.org/10.1177/0269216307081117

[29] Di Leo, S., Beccaro, M., Finnelli, S., Borreani, C. and Costatini, M. (2011) Expectations about Impact of the Liverpool Care Pathway for the Dying Patient in an Italian Hospital. Palliative Medicine, 25, 293-303. http://dx.doi.org/10.1177/0269216310392436

[30] Srivastava, L. and Ting, R. (2014) What Training Do I Get on the Liverpool Care Pathway? British Medical Journal Support, 4, A76-A77. http://dx.doi.org/10.1136/bmjspcare-2014-000654.218

\section{Submit or recommend next manuscript to SCIRP and we will provide best service for you:}

Accepting pre-submission inquiries through Email, Facebook, LinkedIn, Twitter, etc.

A wide selection of journals (inclusive of 9 subjects, more than 200 journals)

Providing 24-hour high-quality service

User-friendly online submission system

Fair and swift peer-review system

Efficient typesetting and proofreading procedure

Display of the result of downloads and visits, as well as the number of cited articles

Maximum dissemination of your research work

Submit your manuscript at: http://papersubmission.scirp.org/ 